\title{
1 The origin and evolution of pollen transport in bees (Hymenoptera: Anthophila)
}

2 Zachary M. Portman ${ }^{1}$

3 1Department of Entomology, University of Minnesota. Email: zpportman@umn.edu

\section{Abstract}

6 The ability to transport pollen from flowers back to the nest represents a key innovation in the 7 evolution of bees from predatory wasp ancestors. Currently, the origin and evolution of pollen 8 transport remains unsettled. Older hypotheses proposed that crop transport was the original 9 mode of pollen transport, but more recent molecular phylogenies have cast doubt on that view. 10 Instead, more recent hypotheses contend that external transport of dry pollen is ancestral in 11 bees. Here, I propose a new hypothesis to explain the origin and subsequent evolution of pollen 12 transport in bees. I propose that pollen transport arose from adult pollen-feeding behavior and

13 that internal transport of pollen is ancestral in bees. This then led to the evolution of external

14 moist transport, which first required a transition step whereby pollen is temporarily accumulated

15 on the venter on a patch of specialized hairs. Finally, external glazed and dry transport evolved

16 from external moist pollen transport, and the evolution of dry transport led to changes in the 17 location of scopae from the original location on the hind tibia and basitarsus. I illustrate many of 18 these hypothetical evolutionary steps using modern-day bee behavior as an example, with a 19 particular focus on the bee Perdita tortifoliae. Examination of the evolution of pollen transport of 20 pollen wasps (subfamily Masarinae) reveals that they have undergone a parallel evolutionary 21 change. Overall, I lay out a broad hypothetical framework to explain the origin and subsequent 22 evolution of pollen transport in bees. This marks a return to the earlier hypothesis that crop 23 transport is ancestral, and it also represents the first in-depth hypothesis to explain how external 24 transport of moistened pollen could have evolved. The evolutionary history of bees has many 25 implications for the biology of bees in the present day, and I lay out a number of predictions that 26 could help confirm or refute my hypotheses.

27 Keywords: Apoidea, pollen gathering, pollen feeding, Perdita, Masarinae 


\section{Introduction}

29 The evolution of bees from predatory wasp ancestors is one of the major evolutionary

30 developments within Hymenoptera. The shift from a predatory to vegetarian lifestyle may

31 explain the relatively rapid diversification of bees compared to their closest relatives (Branstetter

32 et al. 2017, Murray et al. 2018). In addition, the origin of bees approximately 120 mya coincides

33 with the diversification of early flowering plants (Cardinal and Danforth 2013). However, the

34 mechanisms of how bees originally evolved from predatory wasps remains shrouded in mystery.

35 In particular, the shift from hunting prey to gathering and transporting pollen would require major

36 changes in both morphology and behavior.

37 The lack of information on the biology of close relatives of bees, combined with the lack of

38 fossils of early bee lineages, make reconstructing the genesis and evolution of bees difficult

39 (Engel 2001, Michez et al. 2012). Recent molecular phylogenies of Hymenoptera suggest

40 pemphredonine wasps are the sister group to bees (Debevec et al. 2012, Branstetter et al.

41 2017, Peters et al. 2017, Zheng et al. 2018). Sann et al. $(2018,2021)$ pointed to the

42 Ammoplanidae (also known as the pemphredonine subtribe Ammoplanina) as the closest

43 relatives of bees. The biology of relatively few species of Ammoplanidae are known. These

44 wasps are often found on flowers and the few species for which the biology is known provision

45 nests with Thysanoptera (Maneval 1939, Bohart and Grissell 1972). Other related groups

46 provision with Hemiptera, Collembola, or Thysanoptera (Bohart and Menke 1976). Since the

47 prey preferences of such a small number of species are not necessarily representative of all the

48 species in the group, this tells us little information other than the ancestor of bees potentially

49 visited flowers to find prey and needed to use many prey items (and thus provisioning trips) to

50 complete their provisions (Malyshev 1969).

51 One of the most important unanswered questions regarding the genesis of bees is how they

52 evolved to transport pollen from flowers back to the nest. In the present day, there exist multiple

53 modes of pollen transport. Bees can transport pollen either internally (in the crop) or externally

54 on specialized structures composed of specialized hair brushes (scopae) or flattened plates

55 (corbiculae) (Thorp 1979). External pollen transport can be further broken down into three

56 modes: pollen can be transported completely dry, completely moist, or glazed, where moist

57 pollen is packed on top of dry pollen (Portman and Tepedino 2017). The evolutionary sequence

58 between the different modes of pollen transport is currently unsettled and it is not clear why

59 multiple modes of pollen transport exist. 
60 The traditional hypothesis has been that the original bees transported pollen internally in the

61 crop (Müller 1883, Malyshev 1936, 1969, Michener 1965, 1979, Jander 1976, Lanham 1980).

62 However, that hypothesis was based in part on the idea that the family Colletidae was basal due

63 to its short, bilobed glossa, a character shared with many Sphecid wasps (Michener 2007).

64 Because many Colletidae transport pollen in the crop (e.g. Euryglossinae and Hylaeinae), this

65 offered a simple and straightforward solution to the problem of how ancestral, wasp-like bees

66 transported pollen (Michener 1979). However, advances in bee phylogenetics have supported

67 Melittidae, rather than Colletidae, as the basal bee family (Danforth et al. 2006, 2012). The

68 family Melittidae contains no known species that transport pollen internally, causing the crop-

69 transport hypothesis to fall out of favor (Michener 2000, Danforth et al. 2019).

70 More recently, the favored hypothesis is that the original bee transported pollen dry on external

71 scopal hairs (Michener 1944, 2000, 2007, Roberts and Vallespir 1978, Radchenko and Pesenko

72 1996, Westerkamp 1996, Engel 2001). The more detailed explanations of this hypothesis

73 propose that the protobee, "the hypothetical most recent common ancestor of all bees"

74 (Michener 2000), carried pollen on unspecialized hairs over most of the body surface, and then

75 over time the generalized body hairs specialized and coalesced into discrete structures

76 (Radchenko and Pesenko 1996, Michener 2007). For example, in some bees they formed

77 scopa on the abdominal venter (the family Megachilidae) while others formed scopa on the hind

78 legs (the families Andrenidae and Halictidae). However, one of the main problems with this

79 hypothesis is that the wasp ancestors of the original bee likely did not have copious body hairs,

80 as the closest wasp relatives to bees, the pemphredonine wasps, are small and largely hairless.

81 More recently, Sann et al. (2018), pointing to the evolutionary relationship with pemphredonine

82 wasps, proposed that the ancestor of bees could have transitioned to pollen provisioning by

83 carrying pollen-covered thrips. However, they did not propose any actual mechanism to explain

84 how that could have led to scopae and the deliberate transport of pollen.

85 Recently, Portman and Tepedino (2017) questioned the hypothesis that external dry transport is 86 ancestral. This was based on an examination of the patterns of evolution of pollen transport in

87 the genera Perdita (Andrenidae) and Hesperapis (Melittidae); in both genera, it was found that

88 moist pollen transport was the most likely ancestral state and glazed or dry transport were the

89 derived states. This raised the intriguing possibility that external moist transport represents the

90 ancestral state of bees as a whole (Portman and Tepedino 2017). However, we did not propose

91 a potential mechanism for how this could occur, and to date, no studies have proposed an

92 explanation for how moist transport could have evolved, regardless of whether it represents the 
93 original pollen transport mode or evolved from another existing pollen transport mode such as

94 dry transport. The only hypothesis I am aware of that even touches on it is by Michener et al.

95 (1978), which suggests the corbiculae in Apidae arose from ancestral "brushy" scopae on the

96 hind legs, potentially as a way to transport sticky nest materials.

97 Finally, the evolution of the protobee can be informed by the parallel evolution of wasps in the

98 vespid subfamily Masarinae, which have also evolved to provision their larvae with pollen. Bees

99 and pollen wasps both arose around a similar time in the mid-Cretaceous (Branstetter et al.

100 2017, Peters et al. 2017). All known masarid wasps transport pollen in the crop, making it

101 unambiguously the ancestral trait. Further, exploring the differences in their evolution can help

102 explain why bees are so much more diverse than masarid wasps, with approximately 20,000

103 species in bees (Michener 2007) vs. approximately 300 species in Masarinae (Carpenter 2001).

104 The purpose of this paper is to address two specific questions: (1) which mode of pollen

105 transport is ancestral in bees? And, (2) how did the ancestral state of pollen transport diversify

106 into the different modes (internal, moist, dry, glazed) seen in the present day? To address these

107 questions, I follow two primary lines of evidence. First, I use present day bee behaviors

108 (specifically pollen transport, pollen gathering, and pollen feeding) to construct hypotheses

109 regarding how pollen transport originated and transitioned from one mode to another. Second, I

110 examine the biology of masarid pollen wasps, which have undergone a parallel transition to

111 pollen provisioning from predatory ancestors. This approach follows the strategies used by

112 Malyshev (1969) and Jander (1976), but my investigation benefits from recent advances in bee

113 phylogenetics and the greatly increased knowledge of apoid and masarid biology.

114 Unexpectedly, my conclusions match those of Malyshev (1969) and Jander (1976) in supporting

115 crop transport as ancestral in bees. I further propose that external transport of moistened pollen

116 evolved from crop transport, and I propose a sequence of steps that could result in that

117 transition. The evolution of external moist transport from crop transport is supported by three

118 primary lines of evidence. First, the behavioral steps involved in moistening pollen for transport

119 involve extraneous steps that appear to represent evolutionary vestiges. Second, the similarity

120 of the behavioral steps involved in eating pollen and moistening pollen suggest a shared

121 evolutionary origin. Third, I examine parallel patterns of evolution that have occurred in masarid

122 wasps that may represent transitional evolutionary steps that occurred in bees. Finally, I

123 propose that external dry transport evolved from moist pollen transport and that this led to the

124 expansion and migration of scopal hairs in many bee lineages. 


\section{Methods}

126 Observations of bees took place primarily in Utah and Nevada. Perdita tortifoliae Cockerell was 127 observed in the vicinity of St. George Utah, in 2016 and 2017. Macrotera latior (Cockerell) and 128 Hesperapis "timberlakei" (manuscript name from Stage (1966)) were observed in April 2017, in

129 Lake Mead National Recreation Area. Identifications were made with reference the following 130 taxonomic resources: Perdita tortifoliae: Timberlake (1968) and comparison to specimens in the 131 Bee Biology Systematics Laboratory (BBSL) collection; Macrotera latior. Danforth (1996) and 132 comparison to specimens in the BBSL collection; Hesperapis "timberlakei" MS name: Stage 133 (1966) and comparison to specimens in the BBSL collection. Representative specimens were 134 collected and are deposited in the BBSL collection. Collections of bees in Lake Mead National 135 Recreation Area were made under permit \#LAKE-2017-SCI-0004.

136 A Quanta FEG 650 Scanning Electron Microscope was used to image the specimen hairs and 137 videos were taken with a Sony A65 DSLR camera and edited using Sony Movie Studio 13 138 software.

\section{Results and Discussion}

\section{The roadmap}

141 The basic steps in the origin and evolution of pollen transport follow the general sequence of

142 crop transport -> external moist transport -> external dry transport.

143 1. Crop transport represents the original form of pollen transport and evolved from pollen 144 feeding behavior. Bees consumed pollen by nibbling with the mouthparts and by drawing 145 a pollen-covered foreleg through the mouthparts.

2. The next stage of pollen transport evolution was the accumulation of pollen on the venter. The accumulated pollen was then picked up by the foreleg and brought forward to the mouthparts and consumed by drawing the foreleg through the mouthparts.

3. Next, external moist pollen transport evolved from internal transport, likely due to leftover pollen becoming stuck to the hind leg rather than completely groomed off. 
4. External dry and glazed transport evolved from external moist transport in parallel with a development of the scopal hairs, following the hypothesis of Portman and Tepedino (2017).

5. Finally, in various lineages that transport dry pollen, the scopal hairs expanded and migrated from the hind tibia and basitarsus towards the midline of the body. In other lineages, crop transport secondarily evolved.

What follows is a rather meandering discussion of the evidence supporting this roadmap. This is then compared to the hypothesized parallel evolution of pollen transport in pollen wasps.

\section{Hypothesis: Crop transport is ancestral and it evolved from ancestral adult}

\section{pollen-feeding behavior}

In the present day, pollen feeding is an integral part of bee biology; pollen is eaten by adult bees (both male and female) and is necessary for the production of eggs (Robertson 1929, Rozen 1989, 1958, Stockhammer 1966, Shinn 1967, Jander 1976, Batra 1985, Hunt et al. 1991, Richards 1994, Michener 2007, Schäffler and Dötterl 2011, Cane 2016, Cane et al. 2016, Houston 2019). While gathering pollen, females will often take a bite to eat without interrupting pollen gathering activities (Jander 1976, ZP pers. obs.).

The ubiquity and importance of pollen-feeding in bees suggests a basal origin, and it is simple to hypothesize how ancestral pollen-feeding behavior could evolve into transport of pollen in the crop. In this case, it would require adults of the protobee to first consume pollen and nectar (or other plant exudates) for its own energetic and nutritional needs. Despite the limited fossil record, there is direct evidence that aculeate wasps fed on angiosperm pollen for their own

172 nutritional needs as early as the cretaceous (Grimaldi et al. 2019). The next step in the evolution 173 of pollen transport requires the protobee to regurgitate the consumed pollen and nectar back at

174 the nest. The specific behaviors and mechanisms by which regurgitation evolved are unknown.

175 However, regurgitation of food to provision the young has evolved multiple times in multiple 176 different Hymenopteran lineages including ants, pollen wasps and other vespids (Liebig et al. 177 1997).

178 This hypothesis - that crop transport evolved from pollen feeding - has been previously 179 proposed by Malyshev (1969) and Jander (1976). The strongest argument against it is that 180 there are no known examples of basal bees that transport pollen in the crop. However, there are 
181 two points that support this hypothesis: first, essentially all bees that have had their biology

182 explored in depth feed on pollen and regurgitate nectar onto their larval provisions. These two

183 behaviors may represent evolutionary vestiges of ancestral crop transport. Second, as I will

184 explain subsequently, crop transport provides transition steps that are necessary for the next

185 stage of pollen transport: the evolution of external moist transport.

\section{A discussion of the mechanisms by which bees feed on pollen}

187 In order to understand the evolution of pollen transport, it is first necessary to have a thorough

188 understanding of the specific steps bees use to feed on pollen. All known bees consume pollen

189 by drawing the foreleg through the mouthparts (Jander 1976, Michener 2007). Use of the

190 foreleg for consuming pollen represents a modification of typical Hymenopteran grooming

191 behavior. In most other Hymenoptera, the foreleg is cleaned by drawing it through the

192 mouthparts (Farish 1972, Jander 1976). However, in bees, this movement has been co-opted

193 for pollen feeding — indeed, the majority of bee groups have a comb on either the galea or

194 stipes that is specifically used for scraping pollen from the foreleg (Jander 1976). Supporting

195 this hypothesis that ancestral foreleg grooming has been co-opted for pollen feeding is the fact

196 that bees are potentially unique among Hymenoptera in grooming the foreleg by pulling it

197 through the bent midleg (Farish 1972, Jander 1976; see Fig. 3 of Jander 1976 for illustration). In

198 other words, the ancestral method of foreleg-cleaning (drawing it through the mouthparts) has

199 been replaced by a derived method of foreleg-cleaning (drawing it through the crook of the

200 midleg).

201 The use of the foreleg for consuming pollen presents a puzzle since presumably the simplest

202 way to consume pollen would be to nibble it directly with the mouthparts. Indeed, bees are

203 capable of nibbling pollen directly with the mandibles and have been observed to do so when

204 consuming pollen directly from pollen masses in the nest (e.g. Batra 1964), but they apparently

205 do not perform this behavior on flowers (Jander 1976). This is likely because using the forelegs

206 for pollen consumption offers two main advantages: first, it allows consumption of pollen from

207 any place the foreleg can groom, namely the head and thorax (Jander 1976). This allows bees

208 to exploit pollen that has been deposited on the head or thorax by a flower. Second, nibbling

209 pollen presents mechanical difficulty in that pollen is difficult to swallow. In order to be easily

210 swallowed in a large quantity, pollen must be mixed with regurgitated nectar (or potentially some

211 other fluid), a process I have frequently observed performed by bees eating pollen, and pollen

212 feeding behavior is often performed in tandem with nectar concentrating behavior (see Portman 
213 et al. In Press). The hypothesis that feeding on pollen requires a liquid such as nectar is

214 supported by the fact that bees dissected after eating pollen have a mix of pollen and nectar in

215 the crop (Danforth 1989, 1990, Cane et al. 2016). Other pollen-feeding Hymenoptera face this

216 same problem but solve it by a different route: Muttilidae and Scoliidae regurgitate liquid directly

217 onto anthers before consuming the pollen (Jervis 1998).

218 A window back in time: Modern day pollen-feeding behavior is essentially the 219 same as ancestral pollen transport behavior.

220 Eating pollen for adult nutrition and consuming pollen in order to transport it back to the nest are 221 functionally equivalent behaviors. The only real difference is whether or not the bee regurgitates 222 the pollen back at the brood cell (provisioning) or digests it (feeding). As a result, a careful study 223 of the mechanisms by which bees feed on pollen can provide a template for how the protobee 224 transported pollen.

225 Here, I use the bee Perdita tortifoliae as the archetypal bee to demonstrate pollen feeding and 226 pollen gathering behavior. I use this bee primarily because I have been able to make a close 227 and careful study of its pollen-feeding and pollen-gathering habits. Perdita tortifoliae is a minute 228 bee (about $4 \mathrm{~mm}$ body length) that specializes on the pollen of Lepidium (Brassicaceae), which 229 it transports moistened on the hind legs. It occurs in the arid western United States and is locally 230 common in the vicinity of St. George Utah, where observations took place.

\section{Pollen-feeding behavior in Perdita tortifoliae}

232 Similar to other bees, the females of $P$. tortifoliae will occasionally take bites of pollen while 233 gathering pollen and packing it into their scopae. However, towards the end of their daily activity 234 on flowers in the afternoon, $P$. tortifoliae females engage in dedicated feeding trips where they 235 exclusively consume pollen without packing any into the scopa. Indeed, any excess pollen is 236 totally discarded. This feeding trip is presumably the same as feeding trips in other panurgine 237 bees, who return to the nest with empty scopa but have pollen and nectar in the crop (Danforth 238 1989, Neff and Danforth 1991, Visscher and Danforth 1993). These previously observed feeding 239 trips have only been observed through dissecting bees returning to their nests and, to the best 240 of my knowledge, this behavior of feeding on pollen in panurgines has not previously been 241 reported. One of the most important features of the pollen-feeding behavior of Perdita tortifoliae 242 is that the bees first accumulate pollen on a specialized patch of hairs on the venter (as in Fig. 
$2434 \mathrm{~A}-\mathrm{B})$, a strategy that is well-documented in the pollen-gathering behavior of various panurgine

244 bees (Portman et al. 2019).

245 The behavior of pollen feeding can be divided up into five main steps (see also Figure 1 and

246 Supplemental Video 1: https://youtu.be/6M4BpnQ8zfc):

247 Step 1. Accumulating pollen: The forelegs (and occasionally the midlegs) are used to scrape

248 pollen directly from anthers and deposit it on the venter of the thorax.

249 Step 2. Unloading pollen: After a sufficient quantity of pollen has accumulated on the venter

250 of the thorax, the bee rears back on its hind legs, often forming a tripod with the apex of the

251 abdomen. Pollen is removed from the venter by the forelegs using from one to ten downward

252 scraping motions.

253 Step 3. Bringing pollen forward: The legs with pollen are brought to the mouthparts and the

254 tongue is extended, and the bee regurgitates nectar onto the base of the mouthparts.

255 Step 4: Eating the pollen: One at a time, each foreleg is drawn through the mouthparts, either 256 in between the split galeae or between the closed galeae and a mandible.

257 Steps 2-4 are then repeated until the pollen has been removed from the venter of the bee.

258 Step 5: Discarding excess pollen: During the whole process, excess pollen is continuously

259 groomed off of the front legs by scraping them through the crook formed by the inner side of the 260 mid-femur and mid-tibia, and the midlegs are in turn scraped through the crook of the hindlegs.

261 The pollen is then groomed and discarded by the hindlegs rubbing against each other. 


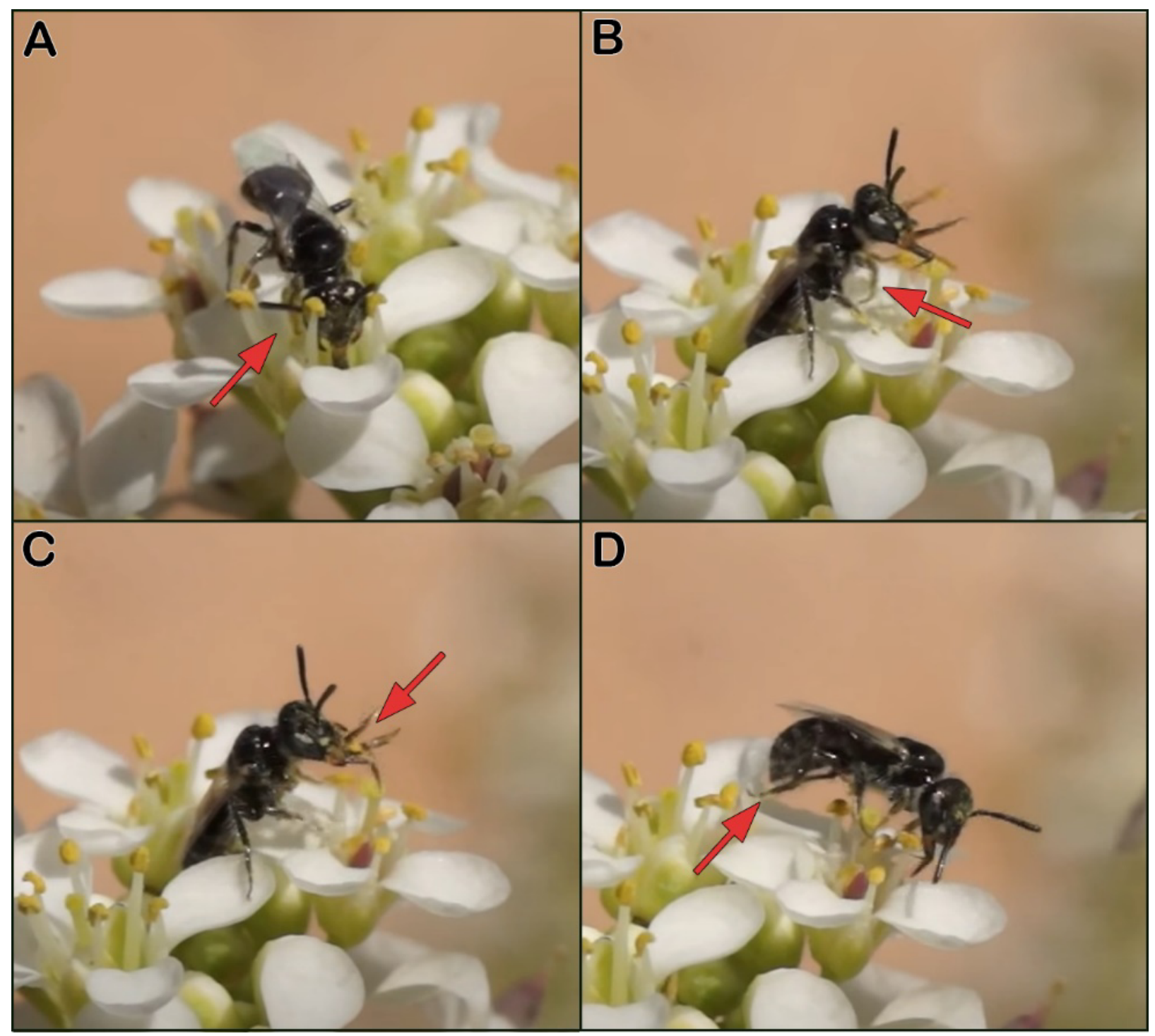

263 Figure 1. Pollen-feeding behavior in Perdita tortifoliae on Lepidium flowers. A) Using the foreleg 264 to accumulate pollen on the venter B) Rearing back and using the forelegs to remove the pollen 265 from the venter. C) Splitting apart the mouthpart and drawing the pollen-covered foreleg through 266 the mouthparts D) Using the hind legs to remove excess pollen. It is much clearer in the video, available as Supplemental video 1: https://youtu.be/6M4BpnQ8zfc

269 Hypothesis: this represents the ancestral form of pollen transport. I propose that this mode 270 of feeding on pollen represents the ancestral form of gathering pollen. It is a key point that the 271 pollen is accumulated on the venter prior to being consumed. It seems probably that the 272 accumulation of pollen on the venter step evolved after pollen transport in the crop, though it 
273 could have evolved before crop transport as a way to more efficiently feed on pollen. However,

274 regardless of when it evolved, it is a necessary preadaptation to evolve external pollen

275 transport. This will be made clear by a comparison of pollen-feeding and external pollen

276 transport in Perdita tortifoliae in the next section.

\section{The evolution of external moist pollen transport from pollen feeding}

278 behavior

279 One of the key points in my argument is that only a couple minor changes are required to turn 280 pollen feeding into external pollen transport. I will demonstrate this here by describing pollen281 gathering and packing behavior of Perdita tortifoliae and comparing it to pollen-feeding behavior 282 in $P$. tortifoliae that was described in the previous section. I then show how pollen-feeding can 283 evolve into external moist pollen transport with just some minor changes.

\section{Pollen gathering and packing behavior in Perdita tortifoliae}

285 Like other panurgines, and similar to how it feeds on pollen, $P$. tortifoliae gathers pollen using a 286 two-step process, where it temporarily accumulates pollen on a specialized patch of apically 287 hooked hairs on the venter of the thorax before transferring it to the hind legs (as in Fig. 4A-B;

288 reviewed in Portman et al. 2019). It also moistens the pollen before packing it onto sparse 289 scopae for transport (Portman and Tepedino 2017). Here, I further break it down into finer steps 290 in order to better illustrate the component behaviors (see also Figure 2 and Supplemental video 291 2: https://youtu.be/v1G96DLynCQ).

292 Step 1. Accumulating pollen: The forelegs (and occasionally the midlegs) are used to scrape 293 pollen directly from anthers and deposit it on the venter of the thorax.

294 Step 2. Unloading pollen: After a sufficient quantity of pollen has accumulated on the venter of 295 the thorax, the bee rears back on its hind legs, often forming a tripod with the apex of the 296 abdomen. Pollen is removed from the venter by the forelegs using from one to ten downward 297 scraping motions.

298 Step 3. Bringing pollen forward: The legs with pollen are brought to the mouthparts, the 299 tongue is extended, and the bee regurgitates nectar onto the base of the mouthparts. 
Step 4: Moistening the pollen: Both forelegs are brought up together and scraped across the top of the extended mouthparts, moving from the base to the apex of the mouthparts and picking up regurgitated nectar in the process.

Step 5: Transferring and packing the pollen back on the hind legs: Immediately following pollen moistening, the foreleg is drawn through the midleg, in a crook formed by the inner side of the mid-femur and mid-tibia, causing the pollen to be transferred to the hind part of the

306 midleg, and the midleg then pats back against the hind tibia, depositing the pollen.

307 Steps 3-5 are then repeated until the pollen has been removed from the venter of the bee.

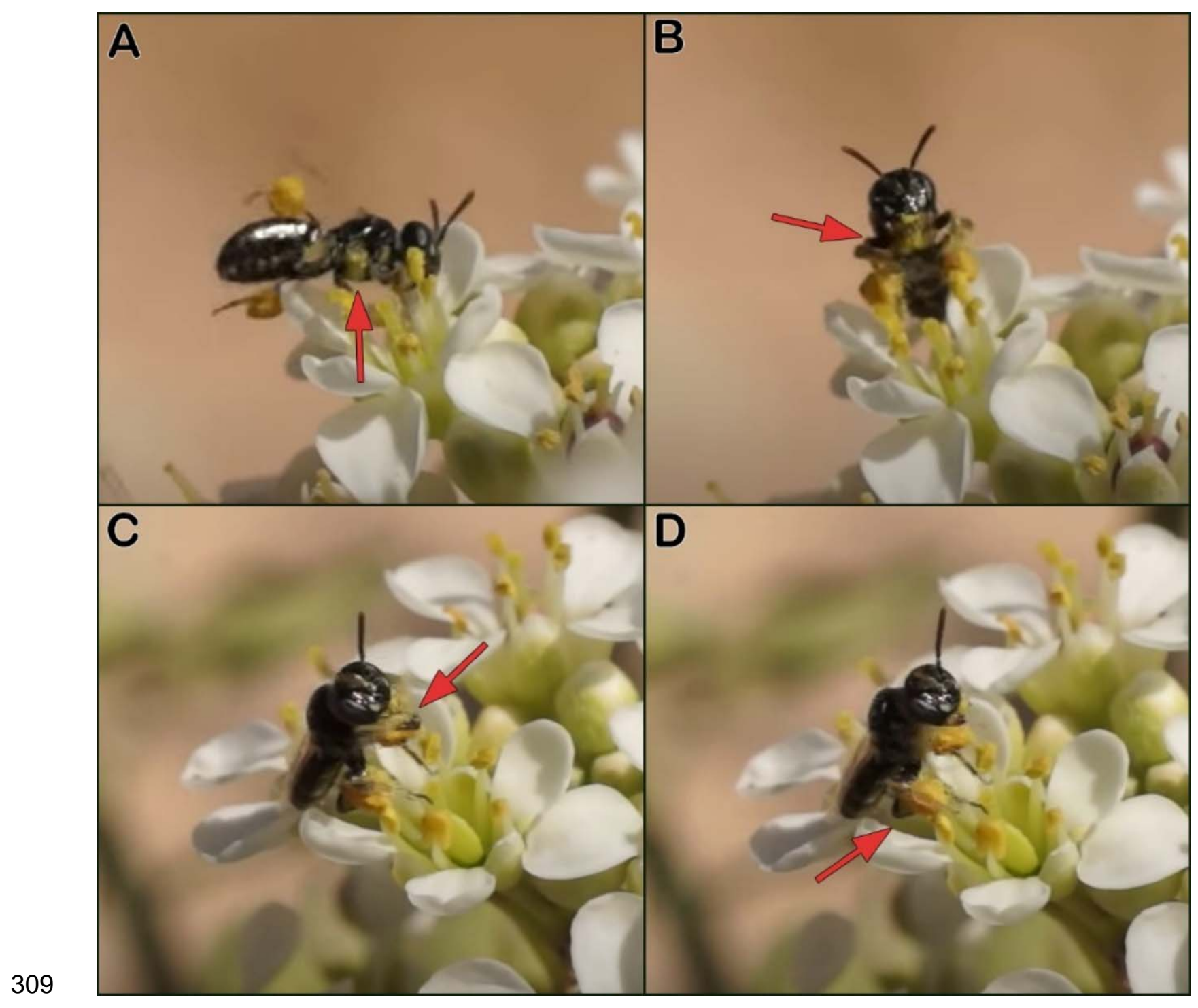


310 Figure 2. Pollen gathering behavior in Perdita tortifoliae. A) Accumulating pollen on the venter.

311 Pollen is visible because the female was just knocked by a male. B) Rearing back and removing

312 the pollen from the venter with the forelegs. C) Drawing the pollen-covered forelegs along the

313 extended mouthparts to moisten them with pollen. D) Using the midlegs to transfer the

314 moistened pollen to the hind legs and tamp it down. It is much clearer in the video, available as

315 Supplemental video 2: https://youtu.be/v1G96DLynCQ

\section{Changing to external moist transport from pollen feeding}

317 Comparing pollen feeding to pollen packing behavior in Perdita tortifoliae (Table 1), two key

318 points are apparent. First, they represent variations on the same basic behavior, and the first

319 three steps are shared between them. Second, only two changes are needed to go from pollen-

320 feeding to pollen-packing: in pollen-packing, the pollen is brought along the mouthparts to be

321 moistened (rather than consumed) and the pollen is packed onto the hind legs (rather than

322 groomed off). As we have seen, when the bee feeds on pollen, a portion of pollen is already

323 passed along the tongue without being consumed, so packing rather than discarding pollen is

324 the primary step that needs to change.

Table 1. Comparing the steps of internal transport (pollen feeding) behavior vs external moist transport behavior

\begin{tabular}{|l|l|l|}
\hline & Internal transport & External moist transport \\
\hline Step 1 & Accumulating pollen & Accumulating pollen \\
\hline Step 2 & Unloading pollen & Unloading pollen \\
\hline Step 3 & Bringing pollen forward & Bringing pollen forward \\
\hline Step 4 & Eating the pollen & Moistening the pollen \\
\hline Step 5 & Discarding excess pollen & $\begin{array}{l}\text { Accumulating pollen on the } \\
\text { hind legs }\end{array}$ \\
\hline
\end{tabular}




\section{Evolutionary implications}

332 Viewing this from an evolutionary standpoint, this provides the map for how external pollen

333 transport evolved; as a modification of crop transport. In essence, external pollen transport

334 represents internal pollen transport with just a couple of modified steps. Both behaviors center

335 around the temporary accumulation of pollen on the venter; the main difference being that in

336 pollen-feeding, the pollen is consumed by the mouthparts and in pollen-gathering the pollen is

337 moistened by the mouthparts and passed back.

338 The steps between pollen-feeding and external pollen transport require few to no transition 339 steps. One could imagine a gradual change where internal pollen transport in the crop slowly 340 changes over to external moist transport. In this case, some of the excess pollen from eating 341 would be passed back and glommed onto the legs rather than groomed off completely. Because

342 this pollen had been in contact with the nectar at the mouthparts, it would be moistened and 343 sticky. The bee would instead wait until it was back at the nest to completely groom it off. This 344 amount of pollen on the legs would grow over time, making up a greater and greater proportion 345 of the pollen load, until eventually, external moist transport became the predominant or sole 346 method of pollen transport.

347 Viewing external moist transport as a behavior that has been tacked onto pollen-feeding 348 behavior explains the incongruous step in pollen gathering behavior, where the bee brings the 349 pollen forward to the mouthparts to be moistened. During that process, the bee picks up the 350 pollen from the venter of the thorax, brings the pollen forward to be moistened at the mouthparts, only to immediately pass the pollen backwards towards the hind legs. This stands in contrast to what seems like the more logical method of simply passing the nectar backwards to moisten pollen (as if often seen in honey and bumble bees). However, bringing pollen forward makes sense because that represents the origin of the behavior from when the bee simply ate the pollen that was brought forward rather than moistening it. In this view, passing pollen forward to the mouthparts to be moistened represents a vestige of the ancestral pollen feeding behavior and this step is retained due to its evolutionary history rather than any particular utility. have evolved without any specialized pollen-carrying structures, as Perdita (and many other bees that transport moistened pollen) carry pollen on short, sparse, and simple scopal hairs. Indeed, the protobee may have been similar in many ways to Perdita tortifoliae: small, relatively 
hairless, and lacking specialized pollen transporting hairs. The one exception to the lack of specialized hairs is the specialized patch on the venter. Though I do not go into it here, the temporary accumulation of pollen on a specialized patch of hairs (e.g. Fig. 4) provides a potential mechanism for bees to specialize on the morphological properties of pollen despite the lack of specialization in the scopal hairs; this is important given that pollen specialization is increasingly viewed as the ancestral state in bees (Michez et al. 2008, Sedivy et al. 2008).

There are still many unknowns about the exact behavior and evolutionary history of the first bees. It is worth noting the possibility that crop transport is not ancestral, and instead external pollen transport evolved directly from adult pollen-feeding behavior (using the same mechanism just outlined). However, I consider that unlikely, particularly given the parallel evolution of pollen wasps, discussed in a later section. In addition, it seems unlikely that feeding on pollen for adult nutrition would generate enough excess pollen to attach in appreciable quantities on the hind legs, especially in an individual that continues to have a predatory lifestyle. It seems likely that the earliest forms of crop-transporting bees are extinct; given that all known bees - including males and parasitics - share a broadened hind basitarsus (Radchenko and Pasenko 1996, Michener 2007). This suggests that the most recent common ancestor of all extant bees transported moist pollen on the hind legs.

\section{Some additional supporting evidence from other bees}

While the behavior of Perdita tortifoliae was used to illustrate the proposed evolutionary sequence of steps in the evolution of pollen transport, they are by no means a special case. They are merely the ones I had the opportunity to observe the most in-depth, and there are additional bees that have these same behaviors. For example, the same pollen-feeding and pollen-gathering behaviors were observed in the species Macrotera latior (Macrotera is the sister genus to Perdita), though their faster speed and tendency to transfer the pollen without standing in a tripod position made the behaviors more difficult to observe and record ( $M$. latior pollen feeding: Supplemental video 3: https://youtu.be/tdUz iTr8qY and M. latior pollen gathering: Supplemental video 4: https://youtu.be/l6C6KtmqSD8). In addition, the practice of temporarily accumulating pollen on the venter is widespread in other panurgine bees, reported in at least 14 other panurgine species, and it has also been recorded in disparate other groups, 392 behavior has not been documented for those species, I see no reason why they would differ 393 from Perdita tortifoliae and Macrotera latior. 
394 The same pollen feeding and gathering behaviors also occur in the melittid bee Hesperapis "timberlakei" Stage (1966) manuscript name (hereafter $H$. "timberlakei"). This bee has a preference for Psorothamnus pollen but also gathers pollen from Larrea (Michez et al. 2008, ZP pers. obs.). It transports moistened pollen on hind leg scopae (Portman and Tepedino 2017). Multiple females of $H$. "timberlakei" were observed gathering pollen from Psorothamnus fremontii, and a short clip of one was recorded (Fig. 3, Supplemental video 5:

400 https://youtu.be/Tpbd2UrmLls). These observations confirm two key aspects of the pollen 401 gathering behavior of $H$. "timberlakel". First, gathered pollen is initially accumulated on the 402 venter of the thorax by the fore- and midlegs. Second, pollen is passed up to the mouthparts to 403 be moistened before being passed back to the scopae (Fig. 3B). Because the transfer of pollen 404 from the venter took place while the bee was in flight, it was very difficult to observe, though the 405 movements can be discerned when the video is slowed down (Supplemental video 6:

406 https://youtu.be/Wzn37N3sNDc). Investigation of the venter of the thorax of $H$. "timberlakel" 407 reveals that, like most Perdita, it has a specialized patch of apically hooked hairs where the 408 pollen accumulates (Fig. 4C-D). Finally, in a subsequent review of old videos, I found one of a 409 Hesperapis (likely H. "timberlakei") feeding on pollen by first accumulating on the venter, but 410 unfortunately only captured a short and obstructed video (Supplemental video 7:

411 https://youtu.be/NK10Jpnzbll).

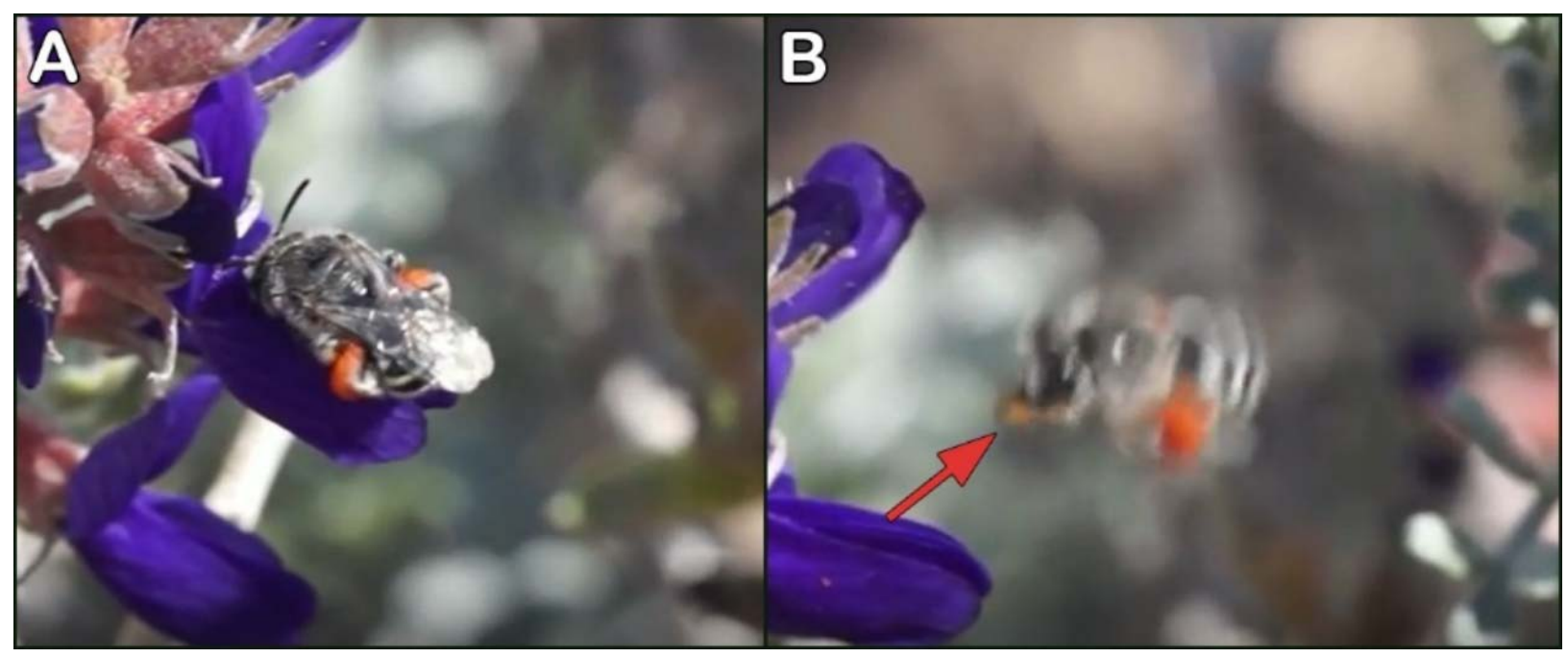

414 Figure 3. Hesperapis "timberlakei" MS gathering pollen A) gathering pollen and accumulating 415 pollen on the venter of the thorax. B) Bringing pollen forward to the mouthparts for moistening 416 whilst in flight; red arrow indicating bright orange Psorothamnus pollen on the foreleg. See 
417 Supplemental video 5: https://youtu.be/Tpbd2UrmLls and Supplemental video 6:

418 https://youtu.be/Wzn37N3sNDc.

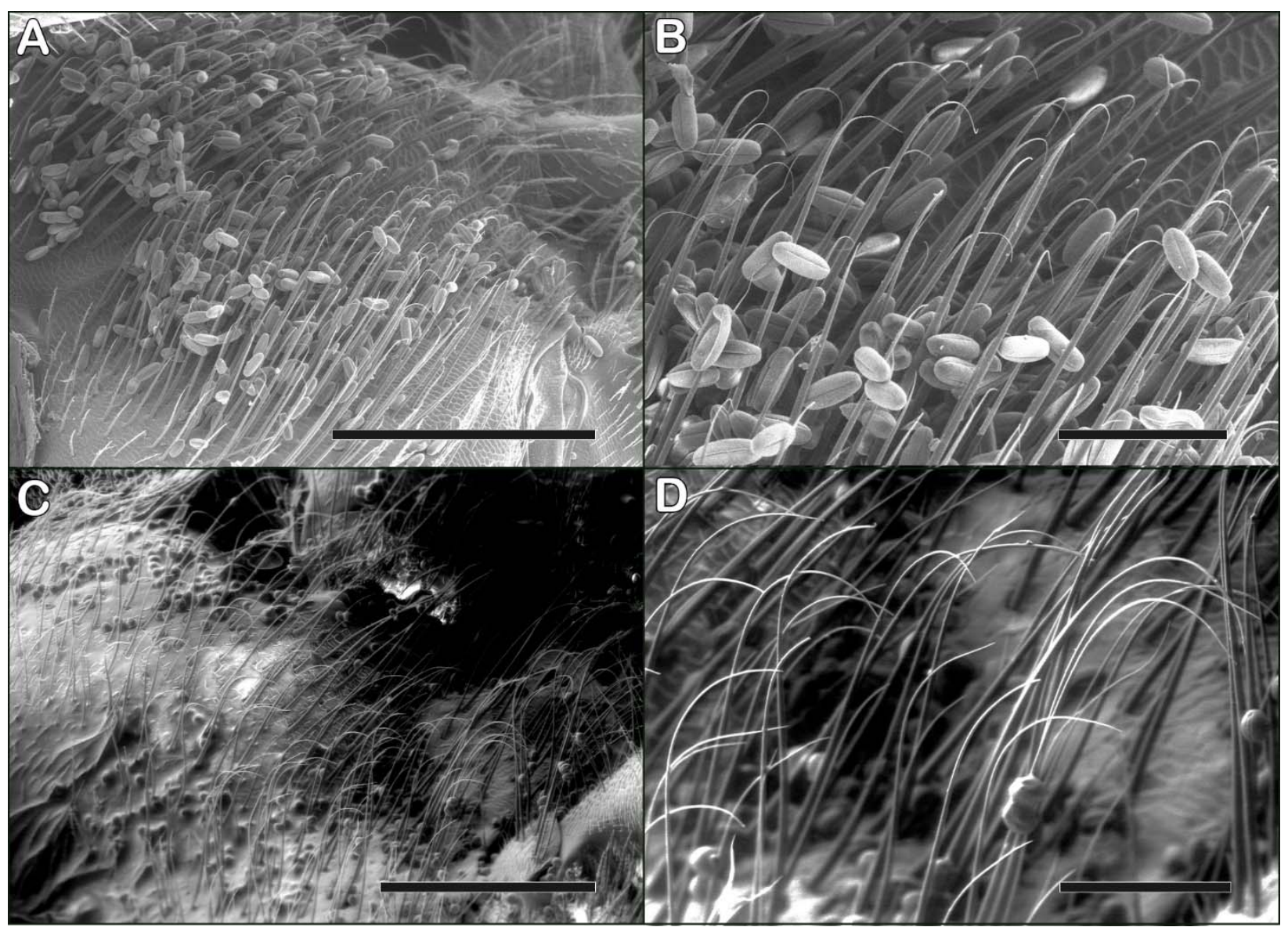

420 Figure 4. Patch of specialized ventral hairs in Perdita perpallida (the ventral patch on $P$.

421 tortifoliae is similar) and Hesperapis "timberlakel" MS. Shown is the venter of the thorax; bees

422 are positioned upside-down and with the head to the left. A) Perdita perpallida, scale bar $=400$

423 um. B) Perdita perpallida scale bar =100 um. C) Hesperapis "timberlakel" MS, scale bar $=400$

424 um. D) Hesperapis "timberlakei" MS, scale bar = 100 um.

426 The similarities between the pollen-gathering and pollen-feeding behavior of $H$. "timberlakel"

427 and $P$. tortifoliae are significant because $H$. "timberlakel" is in the family Melittidae, the basal bee

428 family. This supports the hypothesis that gathering pollen by first accumulating it on the venter is

429 basal as well. Unfortunately, due to the relative rarity of melittid bees, observations of their

430 pollen gathering and feeding behavior are frustratingly sparse. One other Hesperapis species,

$431 H$. laticeps, has been observed temporarily accumulating pollen on the venter, though the pollen 
432 is primarily held in genal hair baskets located on the venter of the head rather than the venter of

433 the thorax (Portman et al. 2019). However, other than the location of the ventral hair patch, the

434 pollen gathering movements are similar between $H$. "timberlakei" and $H$. laticeps, the and the

435 location of the patch on the head is likely an adaptation to extracting pollen from flowers of

436 Mentzelia and Eucnides. Other melittid bees in the genus Macropis, which transport oil-

437 moistened pollen on hind leg scopae, have been found to also gather pollen by accumulating it

438 on the venter before transferring it to the scopae (Cane et al. 1983, Vogel 1992, Schäffler and

439 Dötterl 2011), suggesting this behavior is likely more widespread but unreported in the family.

\section{The evolution of glazed and dry transport from moist pollen transport}

441 The origin of external dry transport likely evolved from moist transport by the stages laid out in

442 Portman and Tepedino (2017). In short, bees that transported moistened pollen underwent an

443 evolutionary transitioned to dry transport by initially packing pollen dry into the scopae before

444 capping it with moistened pollen. This process was facilitated by bees that switched to host

445 plants with adhesive pollen that stayed in the scopae without the need to be agglutinated by

446 nectar. However, due to the short length of the scopal hairs, only a small amount of pollen could

447 be carried dry, and any additional pollen needed to be agglutinated with nectar on top of the

448 initial layer of dry pollen. Over evolutionary time, the proportion of dry pollen gradually increased

449 as the scopal hairs developed and extended and were able to carry greater amounts of dry

450 pollen. One exception occurs in Perdita that utilize Onagraceae pollen - as this pollen has

451 naturally occurring sticky viscin threads that are transported most effectively on sparse, simple

452 scopal hairs (Linsley 1958). The end result of this process was that many bees transitioned to

453 completely dry transport, while other species in the present day retain the vestige of this

454 process and still glaze the pollen, or cap it with moistened pollen. One important point from

455 Portman and Tepedino (2017) is that the evolution of dry transport is associated with

456 specialization on certain pollen types, especially spiky or sticky pollen that either makes moist

457 transport less efficient, dry transport easier, or a combination of both.

458 Glazed pollen transport, where bees initially pack dry pollen into their scopae but then cap it

459 with moistened pollen, appears to be something of a transition state between moist and dry

460 transport (Portman and Tepedino 2017). However, in various species glazed pollen transport

461 appears to be an evolutionary endpoint in and of itself; examples of this include various Perdita,

462 Hesperapis, and Dufourea novaeangliae (Eickwort et al. 1986, Portman and Tepedino 2017). 
No doubt further investigation will reveal more species that transport glazed pollen. It's unclear why some species continue to glaze pollen rather than evolving entirely dry transport.

One important aspect of the evolution of dry pollen transport is that it often leads to the loss of the transition step where bees temporarily accumulating pollen on a specialized hair patch on the venter. However, this behavior is retained in some bees that transport dry pollen. For example, temporarily accumulating pollen on the venter is retained in Macrotera subgenus Macrotera, which transports dry Cactaceae pollen in tibial scopae (e.g. Neff and Danforth 1991), while the rest of the genus transports moistened pollen. However, many other lineages that have switched to dry pollen transport lose the temporary accumulating pollen step, and instead directly pass pollen to the scopae, or even gather pollen directly with the scopae by rubbing or tapping the scopae directly against the pollen source as in many Megachilidae (Portman et al. 2019). The loss of the temporary accumulation of pollen in the pollen gathering process makes the evolutionary transition from moist pollen transport to dry pollen transport a one-way street, since that step is generally necessary to transport moistened pollen.

\section{The further evolution of dry transport and the shifting of the scopal hairs}

The transport of dry pollen is associated with the expansion of the scopal hairs to new areas. All bees that transport moistened pollen transport it exclusively on the hind tibia and basitarsus. The greatest degree of scopal expansion in bees that transport moist pollen is that the pollen carrying area has expanded to the rear of the hind tibia and basitarsus, forming a complete "muff" of pollen that encircles the leg (e.g. Malyshev 1936, Rozen 1989). In contrast, the transport of dry or glazed pollen is often associated with the expansion of the scopal hairs to entirely new areas of the body. For example, in some species, the transport of glazed (partially dry) pollen is associated with the expansion of the pollen-transporting hairs to more proximal hind leg segments (e.g. Portman and Tepedino 2017). In terms of broad-scale evolutionary trends in bees, there is a parallel change in different bee groups, with the scopal hairs expanding or migrating from the distal to the proximal areas of the body. This is most clearly demonstrated in Andrena, Colletes, and various Halictidae, where the majority of pollen is carried on the thorax, sterna, and basal leg segments rather than the hind tibia and basitarsus (Roberts and Vallespir 1978, Michener 1999), which I contend represents the ancestral location

492 of the scopa. Why the scopae have become increasingly proximal is not clear, but it could be an 493 adaptation to better secure the pollen from being scraped off by nesting substrate or forces from 494 wind during flight. 
495 The expansion and migration of scopae is particularly intriguing in the evolution of Megachilidae,

496 which transport pollen on abdominal scopa. For most other bee groups, the migration of the

497 scopae is straightforward, with additional scopal areas being added, but relatively minimal loss

498 of pre-existing scopal structures. For example, in some groups, such as Colletes and Andrena,

499 the scopal hairs of the hind tibia and basitarsus are reduced, but not lost altogether. In most

500 Megachilidae, however, the scopal hairs have moved entirely to the venter of the abdomen

501 without retaining the ancestral scopae. I believe the most likely explanation is that the ancestor

502 to Megachilidae evolved extensive scopal hairs that covered the legs and abdomen (similar to

503 modern-day Systropha), and then the scopae was reduced for some unknown reason, leaving

504 only the abdominal scopae. Some basal groups of Megachilidae, such as the genus Apidosmia,

505 retain scopal hairs on the hind legs (Gonzalez et al. 2012) and may provide clues as to why

506 other Megachilidae have apparently lost hind leg scopae.

507 Another open question is why some bee groups have not undergone significant scopal

508 expansion despite transporting dry pollen. Examples of this include the genera Anthophora and

509 Xylocopa, which transport surprisingly small pollen loads primarily on the hind tibia and

510 basitarsis with only a little bit on the hind femur (Roberts and Vallespir 1978). One potential

511 explanation is that they may supplement the external pollen loads with pollen transported

512 internally in the crop. This is thought to occur in Xylocopa (Roubik 1989), but whether this also

513 occurs in other groups like Anthophora is unknown.

\section{The evolution of oil transport}

515 The evolution of external transport of oil-moistened pollen is unclear and I have not had the

516 opportunity to perform a firsthand investigation of oil-transporting bees. However, some level of

517 inference can still be made about the evolution of this behavior based on known facts. Most

518 importantly, oil-collecting bees also temporarily accumulate pollen on a specialized hair patch

519 on the venter, just like bees that moisten the pollen with nectar. This pollen-accumulating patch

520 appears to be much more extensive in oil-collecting bees; for example, the pollen-accumulating

521 hairs in Macropis take up nearly the entire underside of the bee, including the abdominal sterna

522 as well as the venter of the thorax (Cane et al. 1983, Schäffler and Dötterl 2011). The shared

523 behavior of accumulating pollen on the venter suggests that oil-transport may have evolved

524 from bees that originally moistened with nectar. This hypothesis is supported by the findings that

525 the provisions of oil-collecting bees have been found to contain appreciable amounts of sugars.

526 For example, the provisions Centris maculifrons contains glucose and fructose in addition to oil 
527 (Neff and Simpson 1981), and C. brethesi provisions also contained large amounts of sugars

528 (Simpson et al. 1990). However, for these bees, it's not clear if these sugars came from nectar

529 transported in the crop and later added to provisions, versus whether the scopae also transport

530 pollen moistened with some amount of nectar in addition to oil. More information is needed and

531 the evolution of external transport of pollen moistened with oil remains an open question.

\section{The secondary evolution of crop transport}

533 Despite my hypothesis that internal pollen transport is the original form of pollen transport in 534 bees, most if not all known examples of bees that transport pollen internally represent 535 secondary evolutions of this behavior. There have been two instances where this has been 536 examined in-depth: in the genus Leioproctus (Houston 1981) and in the Colletes fasciatus-group 537 (Kuhlmann 2006). In both cases, the bees evolved from ancestors that transported dry pollen on 538 external scopae (Houston 1981, Kuhlmann 2006). The switch to internal pollen transport is 539 thought to be associated with a switch from hosts with large pollen to small pollen; this switch 540 resulted in scopae that were ill-adapted to carry these fine pollen grains, driving the evolution to 541 internal transport (Houston 1981, Kuhlmann 2006).

542 One intriguing possibility is that internal pollen transport has evolved repeatedly from dry 543 transport because it never quite went away entirely. In other words, at least some bees that 544 transport pollen externally may have never completely lost internal pollen transport and 545 continued to transport a portion of pollen in the crop. Partial internal transport is something that 546 has been mentioned by a couple of authorities on bee behavior and evolution, but to my 547 knowledge it has never been investigated in depth. For example, Roubik (1989) states "A 548 number of nonparasitic bees, for example Ceratina and Xylocopa, appear to collect pollen in 549 both manners [internally and externally] and display a moderate reduction of scopae.

550 Explanations for this behavior are lacking." In addition, Michener (2007) cryptically states:

551 'Finally, although pollen in bees' crops is partly used for their own nutrition, some is carried to 552 the nests and regurgitated." If crop pollen transport was never completely lost, it would help 553 explain why it has been able to evolve repeatedly in disparate bee lineages.

\section{The secondary evolution of moist transport}

555 The secondary evolution of moist transport from dry transport appears to be rare in bees. While 556 there are some relatively well-documented examples of bees evolving dry or glazed transport 557 from ancestors that transported moistened pollen (e.g. Portman and Tepedino 2017), there are 
no well-documented examples of the reverse (though it's not clear how hard anyone has looked). This can be explained, at least in part, by the loss of behavior and structures to accumulate pollen on the venter. Most bees that transport dry pollen have lost the specialized patch of hairs to temporarily accumulate pollen and instead pass the pollen directly to the scopae or even gather it directly with the scopae. Without the temporary accumulation step, the behavior used to moisten the pollen before transferring it to the scopae is lost.

564 However, bees can potentially secondarily evolve moist transport if they develop a different

565 behavior to moisten the pollen. This appears to be the case in at least some Andrena

566 (Dactylandrena) species. For example, within the BBSL collection, there are specimens of

567 Andrena (Dactylandrena) porterae that appear to have moistened pollen in the scopae. These

568 bees gather pollen from the inaccessible flowers of Ribes using the mouthparts. The act of 569 gathering pollen directly with the mouthparts can provide a mechanism to moisten the pollen 570 with nectar that does not require passing the pollen up to the mouthparts to be moistened, as is 571 done when bees temporarily accumulate pollen on the venter. However, there are also many 572 bees that gather pollen with the mouthparts but still clearly transport dry pollen, so the steps 573 driving the secondary evolution of moist pollen transport are not entirely clear and require more 574 investigation.

\section{Parallel evolution in pollen wasps}

576 In addition to bees, an evolutionary change to provisioning the young with pollen from an 577 ancestral predatory lifestyle has arisen in two other hymenopteran lineages. These examples 578 can inform about how this process occurred in bees. The two examples include the masarid 579 pollen wasps in Vespoidea, and the genus Krombeinalictus in Crabronidae. The biology of the 580 single species of Krombeinalictus is poorly known, so the lessons that can be learned from it are 581 limited (Krombein and Norden 1997). However, the biology masarid wasps are relatively well-

582 known, and offer a valuable source of information regarding the evolution of pollen provisioning 583 from an ancestral predatory lifestyle.

584 Using masarid pollen wasps (hereafter referred to as "pollen wasps") as a template, we can 585 compare them to the proposed sequence of bee evolution. This is important because there are 586 many pollen wasps that have a life history similar to the hypothesized protobee. This 587 demonstrates that the proposed stages of bee evolution are not just abstract intellectual 588 constructs, but instead represent viable life-history strategies that exist in the present day. 
Hypothesis: Crop transport is ancestral and it evolved from ancestral adult pollen-

feeding behavior. All known pollen wasps transport pollen internally, making it clear that it is the ancestral form of pollen transport. Similar to what I have hypothesized for bees, internal

592 transport in pollen wasps is thought to have evolved from ancestral pollen feeding behavior, in

593 this case in stem-group vespid wasps that consumed pollen as adults but provisioned their

594 larvae with prey (Mauss 2007). The antiquity of pollen-feeding behavior in adults is further

595 supported by the ubiquity of this behavior in the present day, where adult pollen wasps of both 596 sexes consume pollen for their own nutritional needs (Mauss et al. 2005, 2019). This is most

597 well-documented in males, of which multiple species have been observed collecting pollen and 598 dissections have found pollen in their crop (Mauss and Müller 2000, 2016, Mauss et al. 2003, 5992005,2006 , Groddeck et al. 2004). Because females transport pollen internally, it's difficult to 600 determine whether the pollen they consume is for provisions or their own nutrition. However, 601 dissection of female Pseudomasaris edwardsii revealed pollen in the mid- and hindgut, 602 confirming that they consumed pollen for their own nutrition (Torchio 1970). These examples 603 suggest that pollen consumption is widespread in adult pollen wasps.

604 A discussion of the mechanisms by which pollen wasps feed on pollen. Like bees, pollen 605 wasps gather pollen in two ways, nibbling directly with the mouthparts and by drawing the 606 foreleg through the mouthparts. Nibbling pollen directly with the mouthparts is present in many 607 pollen wasps (Mauss et al. 2019) and likely represents the ancestral form. This type of pollen 608 gathering is most well-documented in Pseudomasaris edwardsii (Torchio 1970, Neff and Hook 609 2007), Quartinia tenerifinia (Mauss and Mauss 2016), and Ceramius hispanicus (Krenn et al. 610 2002). As in bees, nibbling directly with the mouthparts appears to be relatively rare and 611 drawing the forelegs through the mouthparts to consume pollen is the more common form. 612 Indeed, a pollen-comb on the galea has been found in pollen wasps, where it is presumably 613 used to remove pollen from the forelegs as they are drawn through the mouthparts (Krenn et al.

614 2002, Mauss et al. 2019). Multiple species of pollen wasp have been documented to gather 615 pollen through a combination of nibbling with the mandibles and drawing the forelegs through 616 the mouthparts. This is seen in species such as Celonites fischeri (Mauss and Müller 2014), 617 Ceramius fonscolombei (Mauss et al. 2003), Quartinia canariensis (Mauss and Müller 2016), 618 and Quartinia major (Mauss et al. 2018). The use of forelegs in pollen gathering may be related 619 to the accessibility of the pollen; C. hispanicus is reported to nibble pollen when anthers are 620 accessible, and uses the forelegs when they are not (Mauss and Müller 2000, Krenn et al. 621 2002). 
622 Temporary accumulation of pollen in pollen wasps. Similar to bees, many species of pollen

623 wasps also temporarily accumulate pollen, with the pollen initially gathered onto a specialized

624 patch of hairs before being brought to the mouthparts by the forelegs (Müller 1996). The most

625 well-documented examples of the temporary accumulation of pollen in wasps include species

626 that first accumulate pollen on the face, often on knobbed or hooked hairs (Müller 1996, Mauss

627 2006, Mauss et al. 2016). Other pollen wasps accumulate pollen on the dorsum of the thorax via

628 "rasping" behavior (Torchio 1974, Portman et al. 2019). Most importantly, there are pollen wasp

629 species that gather pollen by first accumulating pollen on the venter of the thorax. For example,

630 Rolandia maculata has a specialized patch of stiff hairs with bent tips on the venter of the

631 thorax; this patch accumulates pollen before being ingested using the forelegs (Houston 1995).

632 A similar pollen-accumulating hair patch is found on the venter of Ceramius braunsi (Gess and

633 Gess 1989). Although Gess and Gess (1989) describe the pollen gathering in C. braunsi as

634 being performed solely by the forelegs, without an accumulation step, the accumulation of

635 pollen in the ventral hair patches suggests Gess and Gess (1989) may have missed that

636 behavior.

637 Tying back to bees. Although there are no pollen wasps that are known to transport pollen

638 externally, there are still important parallels to the hypothesized evolution of pollen transport in

639 bees. Specifically, in both bees and pollen wasps, adults feed on pollen for their own nutritional

640 needs and they can consume pollen either through nibbling or drawing the foreleg through the

641 mouthparts. Importantly, crop transport of pollen is unambiguously ancestral in pollen wasps,

642 and some pollen wasps share the behavior of temporarily accumulating pollen on the venter. It

643 is especially striking that there are pollen wasps that gather and transport pollen the same way

644 that Perdita tortifoliae gathers and consumes pollen, which lends credence to the hypothesis

645 that temporarily accumulating pollen on the venter (as exemplified by Perdita tortifoliae in earlier

646 sections) represents an ancestral form of pollen transport in bees. However, masarids have

647 clearly never made the evolutionary transition to external transport. The lack of this evolutionary

648 innovation could help explain why bees are so much more diverse than masarids, despite their

649 similar evolutionary ages. Overall, this supports the hypothesis that bees and masarids followed

650 a similar evolutionary pathway in the initial stages of the evolution of pollen transport.

\section{Conclusion}

652 In this paper I have laid out a hypothesis on the origin and evolution of pollen transport in bees.

653 Under this view, internal transport in the crop represents the original pollen transport behavior 
654 and it evolved from pollen feeding in adults. From there, bees evolved the ability to temporarily

655 accumulate pollen on a specialized patch on the venter of the thorax, which represents a

656 necessary transition stage that led to external transport of pollen moistened with nectar on the

657 hind legs. External transport of dry or glazed pollen then evolved from external moist transport.

658 Finally, the evolution of external dry pollen transport led to the expansion of the scopal hairs in

659 many bee groups. This hypothesis is supported by multiple lines of evidence, particularly by

660 observations on present-day pollen-feeding and pollen-gathering behavior in bees which allow

661 us to reconstruct the evolutionary history of these behaviors. Importantly, comparing the

662 evolution of pollen transport of bees and pollen wasps boosts this hypothesis because it

663 highlights potential paths of parallel evolution and demonstrates that the hypothesized transition

664 forms in bees are actually viable life history strategies that exist in the present day in some

665 pollen wasps.

666 Under the hypothesis laid out here, the evolution of external pollen transport in bees can be 667 reconstructed by examining the steps of present-day pollen gathering behavior. In the present

668 day, the transport of moistened pollen requires a transition step (temporary accumulation of 669 pollen on the venter) that results in pollen taking a complicated and circuitous route: first the 670 pollen is picked up by the forelegs, then transferred to a temporary holding area on the venter of 671 the thorax, this pollen is then picked back up by the forelegs, brought forward to the mouthparts

672 where it is moistened with nectar, passed backwards again where it is scraped off the forelegs

673 by the midlegs before finally being deposited onto the hind legs. However, this process can be

674 explained if it is viewed as the result of external moist pollen transport evolving by simply adding

675 additional behaviors onto internal pollen transport; in moist transport, the original behavior of

676 bringing pollen forward to be consumed by the mouthparts is retained, but instead of being

677 consumed, the pollen is instead moistened and passed back the hindlegs. Most importantly,

678 each individual stage of this evolutionary process is adaptive in its own right. The consumption

679 of pollen via the foreleg and the temporary accumulation of pollen are both behaviors that are

680 seen in the present day in both bees and pollen wasps.

681 My hypothesis that internal pollen transport is ancestral in bees marks a return to the earliest

682 hypotheses regarding the genesis of bees, which was first laid out by Müller (1883) and

683 expanded by Malyshev (1969) and Jander (1976). All of the previous workers cited the hairless

684 bodies, poorly-developed pollen brushes, short tongues, and similarity to sphecid wasps as

685 evidence that Hylaeus represented an ancestral bee group. Although recent molecular

686 phylogenies have made it clear that Hylaeus and other Colletidae are not basal (Danforth et al. 
687 2012), it does not negate the fact that the protobee almost certainly did have many of those 688 characteristics, particularly poorly-developed body hairs and pollen-collecting structures and 689 behaviors. In other words, the fact that Hylaeus are not basal does not invalidate the other 690 logical arguments in favor of crop transport being ancestral. In particular, the parallel evolution 691 with pollen wasps is one of the strongest arguments in favor of crop transport being ancestral, 692 which is further bolstered by the degree of similarity in their evolutionary development laid out in 693 the previous section.

694 Under this framework, I contend that moist pollen transport is ancestral to dry pollen transport.

695 This represents the first detailed hypothesis about how moist pollen transport could have 696 evolved (with perhaps the exception of Michener et al. (1978)), and it marks a deviation from the 697 conventional wisdom that moist transport evolved from dry transport (Müller 1883, Michener 698 1944, Michener et al. 1978, Roberts and Vallespir 1979, Pasteels et al. 1983). The assumption 699 that moist transport is the more derived character seems to stem, at least in part, by the notion 700 that Apidae, and especially honeybees, represent the most advanced or "most derived" bees 701 (e.g. Müller 1883, Jander 1976, Michener 1979). The hypothesis that moist transport represents 702 the ancestral form of external pollen transport makes sense because it does not require specialized morphological characters such as well-developed branched hairs or scopae. Indeed,

704 it allows pollen types of a wide variety of sizes and shapes to be carried on short and sparse 705 simple hairs instead of the scopal adaptations typically seen in bees that transport dry pollen 706 (Roberts and Vallespir 1978, Portman and Tepedino 2017, Danforth et al. 2019). In contrast, the 707 evolution of dry transport from moist transport is associated with the elaboration, specialization, 708 and expansion of the scopal hairs (Portman and Tepedino 2017).

Most importantly, the hypotheses laid out here create a consistent framework that is informed by present-day bee behavior and allows us to make broad predictions about the biology and

711 evolution of bees. The most important of these predictions are laid out below:

1. Additional studies on Melittidae and other basal bees will reveal that most groups transport moistened pollen.

2. Most bees that transport moistened pollen temporarily accumulate pollen on the venter (or gather pollen directly with mouthparts). The obvious exceptions here are Apis and Bombus (but not Trigona s.I., see Michener et al 1978); it's not clear why this is the case but this should be a derived condition. 
3. Additional studies will also reveal that species that gather pollen by accumulating pollen on a patch of specialized hairs on the venter also accumulate on that patch when feeding on pollen.

4. In bee lineages where there has been a transition between moist and dry external transport, moist transport will be found to be ancestral (except when pollen is gathered directly with the mouthparts).

5. The evolutionary transition of moist transport to dry transport will be associated with the use of pollen that is particularly adhesive, large, or spiny, which would make them more efficiently transported dry (e.g. Portman and Tepedino 2017).

6. Investigation of bees that transport pollen externally will reveal bees that transport a portion of pollen internally as well. This is particularly relevant for Melittidae and bees with small scopae.

7. Additional studies of the pollen gathering behavior of pollen wasps will reveal species that gather pollen by temporarily accumulating it on the venter before transferring to the mouthparts (as in Houston 1995).

8. The broad and flattened hind basitarsus, a character shared by all bees that separates them from wasps (Radchenko and Pasenko 1996, Engel 2001, Michener 2007), is a result of that being the location of the original external scopae. This suggests that the most recent common ancestor of all extant bees transported external moist pollen on the hind legs.

9. Evolutionary trends will reveal that bees have undergone an expansion of the area of scopal hairs from the ancestral location on the hind tibia and basitarsus (rather than the reverse - a consolidation onto the hind tibia and basitarsus).

741 The last prediction stands in strong contrast to the primary competing hypothesis regarding the 742 origin of pollen transport, originally proposed by Radchenko and Pasenko (1996) and supported 743 by Michener (2007). Under that hypothesis, external dry transport is ancestral and scopal hairs 744 coalesced and specialized from a diffuse and unspecialized ancestral form. This creates a key 745 difference between their hypothesis and my own. Under my hypothesis, where moist transport is 746 ancestral to dry transport, the hind tibia and basitarsus are the ancestral location of the scopa, 747 and all modern-day external scopae have expanded outward from there. In contrast, under the 748 hypothesis of Radchenko and Pasenko (1996), the reverse would be predicted — that diffuse 
scopae should coalesce on the hind tibia and basitarsus. My prediction that scopae that transport dry pollen will have become increasingly proximal rather than increasingly distal also stands in contrast to the conventional wisdom regarding the evolution of pollen transport (Pasteels and Pasteels 1979, Thorp 1979, Pasteels et al. 1983, Westerkamp 1996). Based on the evidence currently available (e.g. Roberts and Vallespir 1978), expansion of the scopae, rather than the consolidation, appears to be the rule, though this has yet to be rigorously tested from a phylogenetic standpoint.

Here, I have presented the first detailed hypothesis of how external moist transport could have evolved and this marks a step forward in a field that has seen little progress despite the major advances in our understanding of bee phylogenies and deep evolutionary relationships. Further, this framework allows for us to better understand bee biology in the present day, and offers an evolutionary explanation for behaviors, such as the temporary accumulation of pollen on the venter, that may at first seem incongruous. It is my hope that this will stimulate the research needed to confirm or refute this hypothesis. While better-resolved phylogenies would certainly be helpful, answers about the origin and evolution of pollen transport primarily require studies on the natural history, behavior, and functional morphology of bees and related Hymenoptera.

\section{Acknowledgments}

I thank Vince Tepedino for feedback on various drafts of this manuscript. I acknowledge the

768 support from the Microscopy Core Facility at Utah State University for the SEM work. The

769 fieldwork that led to most of the bee observations that form the basis of this work was made

770 possible due to funding by the U.S. Fish and Wildlife Service (Grant F16AP00680).

\section{References}

772 Batra SWT (1964) Behavior of the social bee, Lasioglossum zephyrum, within the nest

773 (Hymenoptera: Halictidae). Insectes Sociaux 11: 159-185.

$774 \quad$ https://doi.org/10.1007/BF02222935

775 Batra SWT (1985) Red maple (Acer rubrum L.), an important early spring food resource for 776 honey bees and other insects. Journal of the Kansas Entomological Society 58: 169-172. 
777 Bohart GE, Menke AS (1976) Sphecid Wasps of the World. University of California Press, 695 pp.

Bohart RM, Grissell EE (1972) Nesting habits and larva of Pulverro monticola. Pan-Pacific Entomologist 48: 145-149.

Branstetter MG, Danforth BN, Pitts JP, Faircloth BC, Ward PS, Buffington ML, Gates MW, Kula

Cane JH (2016) Adult pollen diet essential for egg maturation by a solitary Osmia bee. Journal

Cane JH, Dobson HEM, Boyer B (2016) Timing and size of daily pollen meals eaten by adult

Cane JH, Eickwort GC, Wesley FR, Spielholz J (1983) Foraging, grooming and mate-seeking behaviors of Macropis nuda (Hymenoptera, Melittidae) and use of Lysimachia ciliata

Cardinal S, Danforth B (2013) Bees diversified in the age of eudicots. Proceedings of the Royal (Primulaceae) oils in larval provisions and cell linings. American Midland Naturalist 110:

Carpenter JM (2001) Checklist of species of the subfamily Masarinae (Hymenoptera: Vespidae). 257-264. https://doi.org/10.2307/2425267 Journal of the Kansas Entomological Society 62: 59-79. Available from: http://www.jstor.org/stable/10.2307/25085052.

Danforth BN (1990) Provisioning behavior and the estimation of investment ratios in a solitary bee, Calliopsis (Hypomacrotera) persimilis (Cockerell) (Hymenoptera: Andrenidae). 
Danforth BN (1996) Phylogenetic analysis and taxonomic Macrotera, Macroteropsis,

Danforth BN, Minckley RL, Neff JL (2019) The solitary bees: Biology, evolution, conservation. Princeton University Press, Princeton and Oxford, 472 pp. https://doi.org/10.2307/j.ctvd1c929

Danforth BN, Sipes S, Fang J, Brady SG (2006) The history of early bee diversification based on five genes plus morphology. Proceedings of the National Academy of Sciences 103: 15118-15123. https://doi.org/10.1073/pnas.0604033103

Danforth BN, Cardinal S, Praz C, Almeida E a B, Michez D (2012) The impact of molecular data on our understanding of bee phylogeny and evolution. Annual Review of Entomology 58: 57-78. https://doi.org/10.1146/annurev-ento-120811-153633

Debevec AH, Cardinal S, Danforth BN (2012) Identifying the sister group to the bees: a molecular phylogeny of Aculeata with an emphasis on the superfamily Apoidea. Zoologica Scripta 41: 527-535. https://doi.org/10.1111/j.1463-6409.2012.00549.x

Eickwort G, Kukuk P, Wesley F (1986) The nesting biology of Dufourea novaeangliae (Hymenoptera: Halictidae) and the systematic position of the Dufoureinae based on

Engel MS (2001) A monograph of the Baltic Amber bees and evolution of the Apoidea behavior and development. Journal of the Kansas Entomological Society 59: 103-120.

Farish DJ (1972) The evolutionary implications of qualitative variation in the grooming behaviour of the Hymenoptera (Insecta). Animal behaviour 20: 662-76. Available from: http://www.ncbi.nlm.nih.gov/pubmed/4661314. (Hymenoptera). Bulletin of the American Museum of Natural History 259: 1-192. https://doi.org/10.1206/0003-0090(2001)259<0001:AMOTBA>2.0.CO;2 Available from: http://www.jstor.org/stable/25084743 (June 3, 2014).

Gess SK, Gess FW (1989) Flower visiting by masarid wasps in southern Africa (Hymenoptera: Vespoidea: Masaridae). Annals of the Cape provincial Museums 18: 95-134. Available 
from: https://www.biodiversitylibrary.org/item/215761.

834 Gonzalez VH, Griswold T, Praz CJ, Danforth BN (2012) Phylogeny of the bee family

835 Megachilidae (Hymenoptera: Apoidea) based on adult morphology. Systematic

$836 \quad$ Entomology 37: 261-286. https://doi.org/10.1111/j.1365-3113.2012.00620.x

837 Grimaldi DA, Peñalver E, Barrón E, Herhold HW, Engel MS (2019) Direct evidence for eudicot

838 pollen-feeding in a Cretaceous stinging wasp (Angiospermae; Hymenoptera, Aculeata)

839 preserved in Burmese amber. Communications Biology 2: 1-10.

$840 \quad$ https://doi.org/10.1038/s42003-019-0652-7

841 Groddeck J, Mauss V, Reinhold K (2004) The resource-based mating system of the

842 mediterranean pollen wasp Ceramius fonscolombei Latreille 1810 (Hymenoptera,

$843 \quad$ Vespidae, Masarinae). Journal of Insect Behavior 17: 397-418.

$844 \quad$ https://doi.org/10.1023/B:JOIR.0000031539.52983.89

845 Houston T (2019) A guide to native bees of Australia. CSIRO Publishing, 280 pp.

846 Houston TF (1981) Alimentary transport of pollen in a paracolletine bee (Hymenoptera:

847 Colletidae). Australian Entomological Magazine 7: 57-59.

848 Houston TF (1995) Notes on the ethology of Rolandia maculata (Hymenoptera: Vespidae:

849 Masarinae), a pollen wasp with a psammophore. Records of the Western Australia

$850 \quad$ Museum 17: 343-349.

851 Hunt JH, Brown PA, Sago KM, Kerker JA (1991) Vespid wasps eat pollen (Hymenoptera:

852 Vespidae). Journal of the Kansas Entomological Society 64: 127-130. Available from:

853 http://www.jstor.org/stable/25085261.

854 Jander R (1976) Grooming and pollen manipulation in bees (Apoidea): the nature and evolution 855 of movements involving the foreleg. Physiological Entomology 1: 179-194.

$856 \quad$ https://doi.org/10.1111/j.1365-3032.1976.tb00960.x

857 Jervis MA (1998) Functional and evolutionary aspects of mouthpart structure in parasitoid $858 \quad$ wasps. Biological Journal of the Linnean Society 63: 461-493.

859 https://doi.org/10.1111/j.1095-8312.1998.tb00326.x

860 Krenn HW, Mauss V, Plant J (2002) Evolution of the suctorial proboscis in pollen wasps 
(Masarinae, Vespidae). Arthropod Structure and Development 31: 103-120.

Krombein K V, Norden BB (1997) Nesting behavior of Krombeinictus nordenae Leclercq, a sphecid wasp with vegetarian larvae (Hymenoptera, Sphecidae, Crabroninae). Proceedings of the Entomological Society of Washington 99: 42-49.

Kuhlmann M (2006) Scopa reduction and pollen collecting of bees of the Colletes fasciatus-

Lanham UN (1980) Evolutionary origin of bees (Hymenoptera: Apoidea). Journal of the New York Entomological Society 88: 199-209.

Liebig J, Heinze J, Holldobler B (1997) Trophallaxis and aggression in the ponerine ant, Ponera coarctata: Implications for the evolution of liquid food exchange in the Hymenoptera. Ethology 103: 707-722. https://doi.org/10.1111/j.1439-0310.1997.tb00180.x

Malyshev SI (1969) Genesis of the Hymenoptera and the phases of their evolution. Springer

Linsley E (1958) The ecology of solitary bees. Hilgardia 27: 543-585.

Maneval H (1939) Notes sur les Hymenopteres. Annales de la Societe Entomologique de

Malyshev SI (1936) The nesting habits of solitary bees. A comparative study. Revista Espanola de Entomologia 11: 201-309.

Mauss V (2006) Observations on flower association and mating behaviour of the pollen wasp species Celonites abbreviatus (Villers, 1789) in Greece (Hymenoptera: Vespidae, Masarinae). Journal of Hymenoptera Research 15: 266-269.

Mauss V (2007) Evolution verschiedener Lebensformtypen innerhalb basaler Teilgruppen der Faltenwespen (Hymenoptera, Vespidae). Denisia 66: 701-722. hispanicus Dusmet (Hymenoptera, Vespidae, Masarinae): Nesting, mating, and flower 
associations. Journal of Hymenoptera Research 9: 1-17. Available from: http://biostor.org/reference/251.

Mauss V, Müller A (2014) First contribution to the bionomics of the pollen wasp Celonites fischeri Spinola, 1838 (Hymenoptera, Vespidae, Masarinae) in Cyprus. Journal of

Mauss V, Müller A (2016) Contribution to the bionomics of the pollen wasp Quartinia canariensis Blüthgen, 1958 (Hymenoptera, Vespidae, Masarinae) in Fuerteventura (Canary Islands,

Mauss V, Mauss H (2016) Field observations of the behaviour of the pollen wasp Quartinia

Mauss V, Andreas M, Yildirim E (2003) Nesting and flower associations of the pollen wasp

Mauss V, Müller A, Yildirim E (2005) First contribution to the bionomics of the pollen wasp tenerifina Richards, 1969 (Hymenoptera, Vespidae, Masarinae) at flowers in Tenerife (Canary Islands, Spain). Linzer biologische Beiträge 48: 1327-1332.

Mauss V, Muller A, Prosi R (2006) Mating, nesting and flower association of the east Mediterranean pollen wasp Ceramius bureschi in Greece (Hymenoptera: Vespidae: Ceramius caucasicus. Entomological Science 13: 42-59. https://doi.org/10.1111/j.1479Ceramius fonscolombei Latreille, 1810 (Hymenoptera: Vespidae: Masarinae) in Spain. Journal of the Kansas Entomological Society 76: 1-15.

Mauss V, Müller A, Prosi R (2018) Flower associations and nesting of the pollen wasp Quartinia major Kohl, 1898 (Hymenoptera, Masarinae) in Morocco. Journal of Hymenoptera

Research 31: 15-31. https://doi.org/10.3897/jhr.62.22879 Masarinae). Entomologia Generalis 29: 1-26. https://doi.org/10.1127/entom.gen/29/2006/1

Mauss V, Fateryga A, Prosi R (2016) Taxonomy, distribution and bionomics of Celonites tauricus Kostylev, 1935, stat. n. (Hymenoptera, Vespidae, Masarinae). Journal of Hymenoptera Research 48: 33-66. https://doi.org/10.3897/JHR.48.6884

Mauss V, Kuba K, Krenn HW (2019) Evolution of the multifunctional mouthparts of adult Vespidae. In: Krenn HW (Ed.), Insect Mouthparts: Form, Function, Development and 
Performance. Springer, Cham, Switzerland, 443-478. https://doi.org/10.1007/978-3-03029654-4_14

Michener CD (1944) Comparative external morphology, phylogeny, and a classification of the bees (Hymenoptera). Bulletin of the American Museum of Natural History 82: 151-326.

Michener CD (1965) A classification of the bees of the Australian and South Pacific regions. Bulletin of the American Museum of Natural History 130: 1-362. https://doi.org/10.1086/405376

Michener CD (1979) Biogeography of the bees. Annals of the Missouri Botanical Garden 66:

Michener CD (1999) The corbiculae of bees. Apidologie 30: 67-74.

Michener CD (2000) What was the protobee? Anais do IV Encontro sobre Abelhas: 2-8.

Michener CD (2007) The bees of the world. 2nd ed. Johns Hopkins University Press, Baltimore,

Michener CD, Winston ML, Jander R (1978) Pollen manipulation and related activities and

Michez D, Vanderplanck M, Engel MS (2012) Fossil bees and their plant associates. In: Patiny $S$ (Ed.), Evolution of plant-pollinator relationships. Cambridge University Press, Université de Mons-Hainaut, Belgium, 103-164.

Michez D, Patiny S, Rasmont P, Timmermann K, Vereecken NJ (2008) Phylogeny and hostplant evolution in Melittidae s.l. (Hymenoptera: Apoidea). Apidologie 39: 146-162.

Müller A (1996) Convergent evolution of morphological specializations in Central European bee https://doi.org/10.1051/apido

941 Müller H (1883) The fertilisation of flowers. R. Clay, Sons, and Taylor, London. 
Murray EA, Bossert S, Danforth BN (2018) Pollinivory and the diversification dynamics of bees. Biology Letters 14: 20180530. https://doi.org/10.1098/rsbl.2018.0530

944 Neff JL, Simpson BB (1981) Oil-collecting structures in the Anthophoridae (Hymenoptera):

945 morphology, function, and use in systematics. Journal of the Kansas Entomological Society

$946 \quad 54: 95-123$.

947 Neff JL, Danforth BN (1991) The nesting and foraging behavior of Perdita texana (Cresson)

948 (Hymenoptera: Andrenidae). Journal of the Kansas Entomological Society 64: 394-405.

949 Available from: https://www.jstor.org/stable/25085306.

Neff JL, Hook AW (2007) Multivoltinism and usage of multiple nest substrates in a West Texas sand dune population of Pseudomasaris phaceliae Rohwer (Hymenoptera: Vespidae: Masarinae). Journal of Hymenoptera Research 16: 266-276. https://doi.org/10.5860/choice.48-6651

Pasteels JJ, Pasteels JM (1979) Etude au microscope electronique a balayage des scopas collectrices de pollen chez les Andrenidae (Hymenoptera: Apoidea: Andrenidae). Archives de Biologie 90: 113-130.

Pasteels JM, Pasteels JJ, De Vos L (1983) Etude au microscope electronique a balayage des scopas collectrices de pollen chez les Panurginae (Hymenoptera, Apoidea, Andrenidae).

Peters RS, Krogmann L, Mayer C, Donath A, Gunkel S, Meusemann K, Kozlov A, Podsiadlowski L, Petersen M, Lanfear R, Diez PA, Heraty J, Kjer KM, Klopfstein S, Meier Archives de Biologie 94: 53-73.

Portman ZM, Tepedino VJ (2017) Convergent evolution of pollen transport mode in two distantly related bee genera (Hymenoptera: Andrenidae and Melittidae). Apidologie 48: 461-472. https://doi.org/10.1007/s13592-016-0489-8 behavior in bees (Hymenoptera, Apoidea). Journal of Hymenoptera Research 71: 171208. https://doi.org/10.3897/jhr.71.32671 
971 Portman ZM, Ascher JS, Cariveau DP (In Press) Nectar concentrating behavior in bees (Hymenoptera: Anthophila). Apidologie.

973 Radchenko VG, Pesenko YA (1996) Protobee and its nests: A new hypothesis concerning the early evolution of Apoidea. Entomological Review 75: 913-933.

975 Richards KW (1994) Ovarian development in the alfalfa leafcutter bee, Megachile rotundata.

976 Journal of Apicultural Research 33: 199-203. https://doi.org/10.1080/00218839.1994.11100871

Roberts RB, Vallespir SR (1978) Specialization of hairs bearing pollen and oil on the legs of bees (Apoidea: Hymenoptera). Annals of the Entomological Society of America 71: 619627. https://doi.org/10.1093/aesa/71.4.619

Robertson C (1929) Flowers and insects lists of visitors of four hundred and fifty-three flowers. Science Press Printing Company, Lancaster, PA, 221 pp.

Roubik DW (1989) Ecology and natural history of tropical bees. Cambridge University Press, Cambridge, 514 pp. https://doi.org/10.1016/0169-5347(90)90188-J

Rozen JG (1958) Monographic study of the genus Nomadopsis Ashmead (Hymenoptera: Andrenidae). University of California Publications in Entomology 15: 1-202.

Rozen JG (1989) Life history studies of the primitive Panurgine bees (Hymenoptera:

Sann M, Niehuis O, Peters RS, Mayer C, Kozlov A, Podsiadlowski L, Bank S, Meusemann K,

Sann M, Meusemann K, Niehuis O, Escalona HE, Mokrousov M, Ohl M, Pauli T, Schmid-Egger Misof B, Bleidorn C, Ohl M (2018) Phylogenomic analysis of Apoidea sheds new light on the sister group of bees. BMC Evolutionary Biology 18: 1-15. https://doi.org/10.1186/s12862-018-1155-8 behavior. Apidologie 42: 409-424. https://doi.org/10.1007/s13592-011-0010-3 
999

1000

1001

1002

1003

1004

1005

1006

1007

1008

1009

1010

1011

1012

1013

1014

1015

1016

1017

1018

1019

1020

1021

1022

1023

1024

1025

1026

Sedivy C, Praz CJ, Müller A, Widmer A, Dorn S (2008) Patterns of host-plant choice in bees of the genus Chelostoma: the constraint hypothesis of host-range evolution in bees.

Evolution; international journal of organic evolution 62: 2487-507.

https://doi.org/10.1111/j.1558-5646.2008.00465.x

Shinn AF (1967) A revision of the bee genus Calliopsis and the biology and ecology of $C$. andreniformis (Hymenoptera, Andrenidae). University of Kansas Science Bulletin 46: 753936.

Simpson BB, Neff JL, Dieringer G (1990) The production of floral oils by Monttea

(Scrophulariaceae) and the function of tarsal pads in Centris bees. Plant Systematics and Evolution 173: 209-222. https://doi.org/10.1007/BF00940864

Stage Gl (1966) Biology and systematics of the American species of the genus Hesperapis Cockerell. PhD dissertation. University of California, Berkeley

Stockhammer KA (1966) Nesting habits and life cycle of a sweat bee, Augochlora pura (Hymenoptera: Halictidae). Journal of the Kansas Entomological Society 39: 157-192.

Thorp RW (1979) Structural, behavioral, and physiological adaptations of bees (Apoidea) for collecting pollen. Annals of the Missouri Botanical Garden 66: 788-812. https://doi.org/10.2307/2398919

Timberlake PH (1968) A revisional study of the bees of the genus Perdita F. Smith, with special reference to the fauna of the Pacific Coast (Hymenoptera, Andrenidae). Part VII. University of California Publications in Entomology 49: 1-196.

Torchio PF (1970) The ethology of the wasp, Pseudomasaris edwardsii (Cresson), and a description of its immature forms (Hymenoptera: Vespoidea, Masaridae). Contributed Science, Los Angeles County Museum of Natural History 202: 1-32.

Torchio PF (1974) Mechanisms involved in the pollination of Penstemon visited by the masarid wasp, Pseudomasaris vespoides (Cresson). Pan-Pacific Entomologist 50: 226-234.

Visscher PK, Danforth BN (1993) Biology of Calliopsis pugionis (Hymenoptera, Andrenidae) Nesting, foraging, and investment sex ratio. Annals of the Entomological Society of America 86: 822-832. 
1027 Vogel S (1992) Ölblumen und ölsammelnde Bienen [Oil Flowers and Oil-collecting Bees]. IWF 1028 (Göttingen) https://doi.org/10.3203/IWF/Z-7083

1029 Westerkamp C (1996) Pollen in bee-flower relations: Some considerations on melittophily. Botanica Acta 109: 325-332. https://doi.org/10.1111/j.1438-8677.1996.tb00580.x

1031 Zheng B, Cao L, Tang P, van Achterberg K, Hoffmann AA, Chen H-Y, Chen X, Wei S (2018)

1032 Gene arrangement and sequence of mitochondrial genomes yield insights into the phylogeny and evolution of bees and sphecid wasps (Hymenoptera: Apoidea). Molecular 